\title{
HISTÓRIA, EPISTEMOLOGIA MARXISTA E PESQUISA EDUCACIONAL BRASILEIRA
}

\author{
MARISA BiTTAR* \\ Amarilio Ferreira JR.*
}

\begin{abstract}
RESUMO: A partir das últimas décadas do século $\mathrm{xX}$, notadamente com a crise do marxismo, o campo da história da educação passou a contar com a hegemonia da Nova História. Desde então, os objetos de estudo passaram a privilegiar a história das mentalidades, da vida cotidiana, das mulheres, do microacontecimento educacional etc. A "história em migalhas" em que se transformou grande parte da história da produção acadêmica nessa área está diretamente relacionada com a concepção historiográfica que abandonou a preocupação com os movimentos que explicam a totalidade societária e que, por sua vez, se restringe apenas às propriedades únicas, singulares, inerentes a cada um dos fenômenos educacionais estudados. Além disso, os pesquisadores da educação filiados a essa concepção historiográfica tratam o contexto histórico mais geral da sociedade capitalista como um elemento dado da realidade educacional brasileira e, portanto, desnecessário de ser investigado do ponto de vista das contingências históricas que condicionam o cotidiano das práticas pedagógicas.
\end{abstract}

Palavras-chave: História. Epistemologia marxista. Pesquisa educacional.

\section{History, MarXist epistemology and Brazilian EDUCATIONAL RESEARCH}

ABSTRACT: From the last $20^{\text {th }}$ century decades on, especially with the crisis of Marxism, New History has become hegemonic in the field of the history of education. The study objects then began to

* Doutora em História Social e professora titular de História da Educação da Universidade Federal de São Carlos (UfSCAR). E-mail: bittar@ufscar.br

** Doutor em História Social e professor de História e Filosofia da Educação da UfSCAR. E-mail: ferreira@ufscar.br

Educ. Soc., Campinas, vol 30, n. 107, p. 489-511, maio/ago. 2009 
privilege the history of mentalities, everyday life, women, micro-educational events, etc.. Much of the academic production in this area was transformed into a "History in crumbs" directly linked to a historiographic conception that has renounced to the concern over the movements explaining society and restrained to unique, singular properties inherent in each educational phenomenon studied. Moreover, education historians who have subscribed to this conception address the broader historical context of capitalist society as a given datum of Brazilian educational reality, which, therefore, needs not be investigated from the point of view of historical contingencies that affect the daily practices of teaching.

Key words: History. Marxist epistemology. Educational research.

\section{Introdução}

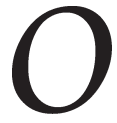

objetivo deste artigo é explicitar a contribuição que a concepção marxista da história pode prestar à pesquisa em história da educação, especialmente se levarmos em consideração a crise que os ditos "velhos paradigmas" epistemológicos sofreram durante as últimas décadas do século passado e a emergência dos chamados "novos" métodos de interpretação da história. Marcados pela ideologia pós-moderna, mas com origem anterior à referida crise, os "novos paradigmas" ganharam relevância e alcançaram posição hegemônica no âmbito da história e, por extensão, na história da educação. O declínio da influência do marxismo e a ascensão da pós-modernidade engendraram outra maneira de produzir o conhecimento histórico, pois foram abandonadas as preocupações explicativas do sentido da totalidade na qual se inserem os objetos das pesquisas. Dito de outra forma: os ideólogos da pós-modernidade desconceituaram o significado histórico da multiplicidade de mediações complexas e contraditórias que explicam a realidade objetiva da sociedade e, também, a independência e a vinculação dos fenômenos ligados entre si de maneira completamente diversa. ${ }^{1}$

Assim, no âmbito da produção acadêmica em educação, assistiu-se a um processo de pulverização da pesquisa em micro-objetos fragmentados e isolados dos fenômenos econômicos, sociais e políticos que animam as relações capitalistas de produção, ou seja, desconectados da "última instância" que estabelece o traço distintivo, a dominação 
geral do todo sobre as partes: a totalidade capitalista na qual os mesmos objetos de pesquisa estão imersos.

Para os chamados paradigmas epistemológicos emergentes, a história da sociedade humana não se explica pelas relaçóes socais de produção; pela lógica do desenvolvimento da forças produtivas; pelo conflito que se estabelece entre as classes sociais antagônicas; pelo papel de controle econômico e ideológico que o Estado assume no âmbito da sociedade de classes; pela relação dialética existente entre sociedade civil, sociedade política e Estado; pela capacidade de autonomia e criatividade que as instituições superestruturais gozam frente às relações sociais de produção da vida material. Na perspectiva dos "novos paradigmas”, esses traços mais estruturais das sociedades humanas perderam a sua validade no processo de construção do conhecimento histórico. Além disso, os acontecimentos históricos ficaram reduzidos a fenômenos fugazes e engendrados por movimentos desconectados de qualquer tipo de sistematização epistemológica que privilegia o sentido de totalidade. A negação dos princípios, leis e categorias consagradas pelos paradigmas epistemológicos que deitavam liames na tradição do pensamento moderno produziu uma fratura mecânica entre os elementos constitutivos da totalidade e as características singulares que plasmam todo e qualquer fenômeno gerado pela sociedade dos homens. Os paradigmas pós-modernos isolaram o singular do geral e, por conseguinte, abandonaram a particularidade fenomênica como categoria de mediação existente entre os elementos da totalidade que perpassam as características individuais dos objetos de pesquisa.

Por consequência, assistiu-se também a uma nova priorização dos fenômenos históricos que deveriam ser alçados à condição de objetos de investigação. A valorização que criou uma nova hierarquia dos estudos históricos ficou marcada pela efemeridade dos objetos de investigação, em detrimento das grandes temáticas da história da educação brasileira, confirmando o que Bourdieu (2001, p. 36) já havia assinalado sobre a "hierarquia social dos objetos". Para ele, "a redundância observada nos domínios mais consagrados" é "o preço do silêncio que paira sobre outros objetos”. A análise do sociólogo francês é perfeitamente aplicável à pesquisa educacional brasileira, campo no qual se observa, cada vez com mais frequência, a reincidência sobre determinados objetos, enquanto outros, igualmente ou mais importantes, foram simplesmente abandonados. 
$\mathrm{Na}$ atual hegemonia, quanto mais desconectados, fugazes, isolados, tênues, rarefeitos, fortuitos, bizarros e excêntricos forem os objetos de pesquisa, mais eles serão nobres e relevantes para o conhecimento histórico. Nessa perspectiva, ganharam proeminência investigativa os fenômenos de natureza cultural, pois o mundo cultural é interpretado como uma nuvem de fenômenos desprovida de qualquer conexão que possa contar com um sentido explicativo lógico. Assim, as manifestaçōes culturais se expressam com base nelas mesmas, desconectadas da materialidade que as originou e, portanto, não guardam qualquer forma de relação com os elementos que dão movimento à totalidade societária. A concepção culturalista da pesquisa também logrou êxito no campo da história da educação e, particularmente, na linha que investiga as instituiçôes escolares. Muitos estudos resultantes dessas pesquisas deixaram de lado a relação entre sociedade e escola e privilegiaram exclusivamente elementos pedagógicos isolados até mesmo do próprio mundo interno das instituiçôes escolares. Os resultados se constituem, na maioria das vezes, em micro-histórias da educação que não dão conta de explicar nem mesmo o próprio sentido do objeto investigado.

Notamos, assim, uma tendência que privilegia o pontual e o episódico, e isto talvez se deva, em parte, à rejeição a uma interpretação marxista anterior que, estabelecendo a crítica justa às contradiçôes da sociedade capitalista, acabava negligenciando a especificidade da educação, restringindo-se, muitas vezes, às explicaçôes paradigmáticas. Essa concepção, por compreender a escola unicamente como aparelho ideológico de Estado, não a elegia como objeto de estudo. Além disso, em contraste com a posição idealista que marcara a área até os anos de 1970, atribuindo a ela função redentora, gerava descrença no papel da educação.

Os fundamentos da pesquisa em história da educação a partir dos anos de 1990

O início da última década do século xx foi marcado pela derrocada do "socialismo real", cujos momentos marcantes foram a queda do muro de Berlim (1989) e o fim da União Soviética (1991), notadamente porque estes dois episódios resultaram, no plano das idéias políticas e filosóficas, em interpretações sobre a possibilidade de que a História havia chegado ao fim e, por conseguinte, o capitalismo vitorioso era a última forma de organização societária existente na face da terra. 
Ou, como afirmara Paulo Schilling, ainda na primeira metade da década de 1990:

Nos últimos anos, especialmente depois do melancólico fracasso das experiências do "socialismo real", falou-se muito em "fim da história". Partindo das conclusões de Alexandre Kojève, o grande intérprete de Hegel, Francis Fukuyama, inicialmente num artigo publicado em 1989, posteriormente ampliado no livro "O fim da história e o último homem" (1992), afirma que a democracia liberal podia constituir o "ponto final da evolução ideológica da história" e "força final do governo humano". E justificava: "enquanto as formas mais antigas de governo se caracterizavam por graves defeitos e irracionalidades, que as levavam ao colapso final, a democracia liberal estava aparentemente livre das contradições internas fundamentais". (Schilling, 1994, p. 7)

O rebatimento dessas interpretações "pós-socialismo real" teve um efeito avassalador no campo epistemológico: chegou-se a decretar o fim da própria História, bem como o fim da capacidade explicativa do marxismo, pois uma determinada interpretação dele estava ideologicamente vinculada à experiência histórica transcorrida após a Revolução Russa de 1917. Assim, de roldão, conceitos como totalidade, verdade, classes sociais, universalidade, nação, Estado, história e metas da história passaram a ser alvo da investida dos "novos críticos". Em síntese: toda a herança racional sistematizada desde o Iluminismo e as suas respectivas utopias. Em seu lugar instaurou-se uma visão fragmentada do mundo, caracterizada pela difusão, dispersão, indeterminação, mutação e "relativismo afim", expressão mais emblemática produzida pelos ideólogos dos "novos paradigmas". A onda de críticas aos "velhos esquemas interpretativos", valorizando o fragmentário, o efêmero e o imaginário, impregnou o ambiente acadêmico no final dos anos de 1980 e na década de 1990. Essa nova forma de se conceber o conhecimento histórico foi analisada por Zaidan Filho (1989, p. 71-72) do seguinte modo:

Ora, essa maneira de ver a História responde por uma certa característica intertextual, interdiscursiva, da "nova" historiografia, recuperando um certo neokantismo comum às filosofias da vida, da experiência, da intuição etc. Caímos outra vez no domínio de uma historiografia nominalista que reduz a História à experiência íntima do historiador e proclama solenemente a incognoscibilidade absoluta do mundo histórico. Mas esse aspecto da "nova" História aparece também ligado ao afrouxamento das barreiras entre História e Literatura, História e Arte, História e Mito. Que 
significado pode ter o recuo de tais barreiras? Por um lado, o combate à apologia do existente, feita indiretamente pela pseudoneutralidade do positivismo; por outro, o combate às "grandes sínteses" deterministas, teleológicas da História - identificadas com bastante ênfase com o marxismo atual. O novo historiador recorre ao exemplo da criação literária e artística, para resgatar a dimensão crítico-utópica do seu ofício - sepultada pelo positivismo e por certas apropriações teóricas e práticas do marxismo.

Nessa perspectiva, na qual o mundo subjetivo ganha proeminência, os estudos históricos passaram a se preocupar mais com a forma da linguagem do que propriamente com os determinantes econômicos, sociais, políticos e culturais. Além disso, postularam um relativismo absoluto do conhecimento e, por conseguinte, realçaram os valores da linguagem poética e literária como os instrumentos realmente fecundos para se desvelar a "verdade histórica". Por extensão, o texto histórico ficou polissêmico e ambíguo, já que se transforma em literatura, crítica literária ou poesia. Em síntese: ele acaba por não conseguir afirmar coisa alguma e todos esses campos do conhecimento saem perdendo: perde a história porque abandona o acontecimento gerado pelas múltiplas contingências humanas e, consequentemente, perde também a poesia porque não pode radicalizar a sua capacidade de perscrutar as profundezas da subjetividade humana.

Assim, para além da reestruturação tecnológica sofrida pelas relações capitalistas de produção durante as duas últimas décadas do século passado, o novo modelo gerador do conhecimento histórico, assentado na crítica ao positivismo ${ }^{2}$ e às "apropriações teóricas e práticas do marxismo" não-dialético, ${ }^{3}$ alastrou-se no âmbito da academia, onde os seus defensores, não raro, bradavam contra o "terrorismo e a intolerância dos saberes constituídos”. Contudo, uma vez conquistando posição de poder hegemônico no mundo acadêmico, os novos ideólogos da Oficina de Clio exerceram "feroz intolerância e patrulhamento ideológico", tal como registrou o historiador Ciro Flamarion Cardoso (1994, p. 74). Quanto ao aspecto estritamente epistemológico, todas as tendências denominadas pós-modernas, incluindo as formas mais extremadas da "Nova História", foram convidadas a limitar-se a modos de trabalhar apenas aquilo que valorizava exclusivamente os aspectos simbólicos dos fenômenos estudados, ou seja, reduzidos unicamente aos episódios passivos de serem interpretados no âmbito limitado da crítica cultural. Com isso, se retomou, segundo Cardoso (1994, p. 68), as 
(...) construções idealistas em que o significado do passado é visto como um "texto" geertiziano [Clifford Geertz] em relativismo contextualizado. De acordo com o ponto de vista ou postulado hermenêutico, cada interpretação cria um novo significado, o que conduz à relativização completa de todas as categorias como meros símbolos desprovidos de quaisquer conteúdos materiais. Mesmo o poder, num certo sentido, não existe (...). Em suma, essa perspectiva implica um achatamento reacionário e culturalista do mundo em "símbolo" e em "texto".

Todavia, se tal postura se difundia no âmbito da história da educação era porque a mesma tendência já atravessava o campo da pesquisa em história. No apogeu da afirmação ideológica pós-moderna que predominou na última década do século xx, Cardoso (1995, p. 5) prognosticava que:

O paradigma pós-moderno avançou no Brasil, o que a meu ver é um retrocesso em termos gerais, não em todos os termos. O problema é que, na França, por exemplo, ao começar essa moda das mentalidades e de coisas similares, eles já tinham mapeado o país em termos de uma História Econômica muito detalhada, região por região, já tinham usado os arquivos a fundo, portanto tinham uma idéia bastante boa de como era a História Econômica e Social da França (...). Não é que eu tenha nada contra essas temáticas em si (quanto à maneira de abordá-las talvez). Acho que é uma pena você abandonar, fazer tábua rasa do outro, quer dizer, que o outro sofra de descontinuidade. Temas considerados importantes são simplesmente abandonados, não interessam a mais ninguém, o debate que não tinha se concluído, nem tinha chegado a nenhuma conclusão lógica, simplesmente pára no meio e não se volta mais a isso.

No mesmo diapasão, Luis Felipe de Alencastro alertava para o fato de que ocorrera um mal entendido muito grande quando se incorporou acriticamente as novas tendências francesas para a nossa historiografia. Ele aludia à perda da tradição das grandes obras de interpretação do Brasil, afirmando que:

(...) um pouco disso se deve a uma interpretação equivocada que se fez no Brasil da "École dos Annales" e do que é chamado de "Nova História” francesa. A discussão na França se dá num terreno bem balizado, com a retaguarda de uma historiografia bem estabelecida, um ensino de história muito eficaz no secundário e nas universidades e uma história positivista muito bem sedimentada, com datas, personagens etc. Quando a "École dos Annales" começou a combater isso, já antes da Segunda 
Guerra, ninguém pensou, como se fez por aqui, que as datas não tinham a menor importância. É um mal entendido sem tamanho. Nenhum desses historiadores franceses, como Jacques Le Goff, Duby e outros, é só especialista em mentalidades. São também especialistas em história econômica e história política. A base deles é essa. Sem levar isso em conta, no Brasil se perdeu a idéia de "última instância". O historiador estabeleceu uma equivalência total dos fatores e sua análise se descompromissou inteiramente de arbitrar uma certa hierarquia de fatores. (Alencastro, 1994, p. 7-8)

A tendência epistemológica assentada na perda da "idéia de última instância" e na ausência de "uma certa hierarquia" entre os objetos de pesquisa no âmbito da história da educação também foi criticada por Dermeval Saviani. Em 1995, analisando esses equívocos no âmbito da pesquisa em educação, ele concluiu que esta havia atingido certo nível de consolidação institucional e que o quadro era mais favorável, mais sólido do que no passado, mas que, paradoxalmente, era

(...) mais precário em função dessa onda dita neoliberal, desse modismo, dessa tendência irracionalista. A pesquisa também sofre o impacto dessas tendências e, nesse sentido, como essas tendências são desagregadoras, a idéia de totalidade se perdeu, então a pesquisa educacional é alvo disso. Hoje é interdisciplinaridade, multidisciplinaridade, cotidiano. Noções que você fica se perguntando de onde vieram e até se o próprio autor tem consciência do que está sendo dito. Às vezes é mais modismo. É não sei o que, nas dobras do cotidiano... Dobras do cotidiano! (Saviani, 1995)

Da mesma forma, na França, berço da Escola dos Annales, essa reflexão também já vinha sendo empreendida e localizava a origem da nova hegemonia nas correntes derivadas daquela Escola e que passaram a constituir a "Nova História", a partir do final da década de 1960. Era o caso do historiador francês François Dosse, que sinalizava para o risco da perda da dimensão política da história, no momento mesmo em que a ascensão dos "novos paradigmas" ocorria. Quando de sua visita ao Brasil, para participar de um encontro de historiadores, Dosse (1995, p. 12) concedeu uma entrevista ao jornal Folha de S. Paulo, chamando a atenção para o plano teórico e epistemológico da Escola dos Annales e discordando da noção de história imóvel, da negação do acontecimento, da longa duração e da determinação da geo-história, pois isso se chocava com tudo que era descontinuidade, ruptura, fato. 
Para ele, que havia vivido o maio de 1968, expulsar os acontecimentos e a dimensão propriamente humana da história parecia impensável.

Entretanto, de onde vinha essa tendência historiográfica? Para localizá-la, voltemos aos fundadores da Escola dos Annales e às suas gerações. Esta Escola surgiu em 1929, na França, a partir da criação da revista Annales d'Histoire Économique et Sociale, dirigida pelos historiadores Marc Bloch e Lucien Febvre, e que vinha sendo planejada desde o final da Primeira Guerra Mundial. Suas críticas se dirigiam à história fatual, positivista e patriótica que então se produzia e nisto, portanto, a Escola estava muito próxima do marxismo, embora também se aproximasse da visão objetivista da sociologia de Émile Durkheim (Dosse, 1992, p. 45-46). Os fundadores, influenciados pelas ciências sociais, propunham o abandono do acontecimento, em benefício de estudos que relacionassem o homem, seu tempo e o espaço, a partir de perguntas formuladas pelo presente. Ao contrário dos positivistas, para quem sem documento não há história, os fundadores da Escola dos Annales afirmavam que sem problema é que não há história. Essa problematização deveria ser feita a partir de perguntas sobre o passado, propondo, ao mesmo tempo, que a história não mais fosse entendida como ciência apenas do passado, mas também do presente, inclusive o conhecimento do presente era condição da cognoscibilidade de outros períodos históricos.

$\mathrm{Na}$ década de 1950 e sob a influência do estruturalismo, Fernand Braudel introduziu a noção da longa duração, privilegiando o estudo dos sistemas e não mais das mudanças, como preconizava Marc Bloch. Adotando a perspectiva de geografia histórica de Lucien Febvre, ele aprofundou a preocupação com o espaço. Seu magistral estudo sobre o Mediterrâneo e Felipe II, por exemplo, começa tratando de uma história quase sem tempo e sem gente, mas na qual, aos poucos, surge a história da estrutura econômica, social e política e, finalmente, a movimentada história dos acontecimentos. Considerando esse estudo como referência, concluímos que as duas primeiras gerações dos Annales não excluíram os acontecimentos da história, mas os trataram de forma distinta à do positivismo, situando indivíduos e eventos em seu meio, uma vez que, para Braudel, "a história dos acontecimentos é a superfície da história" (Burke, 1991, p. 104). Nessa perspectiva, ele não desconsiderou os acontecimentos em sua obra, embora seu interesse residisse em realidades mais profundas, as correntes abaixo da superfície, conforme analisou Burke. Certamente, são esses traços que levam Cardoso (1997, p. 9) a 
classificar a produção da Escola dos Annales, de 1929 a 1969, como mais próxima do marxismo do que a derivada de interpretações como a de Louis Althusser e a da Escola de Frankfurt.

A partir de 1969 começou a ser gerada a "Nova História", com a proeminência de alguns jovens como André Burguière e Jacques Revel. Embora essa geração reivindique uma continuidade com os Annales, é então que começa, de fato, a ser elaborada a historiografia hoje hegemônica, a qual, segundo Cardoso (1997, p. 9), não guarda relação com os postulados de Bloch, Febvre e Braudel. A partir daí ocorre a proeminência das tendências historiográficas que negam totalmente o acontecimento, passando a privilegiar aspectos concernentes aos elementos que conferem "um entendimento íntimo do ser humano" e é neste sentido que o historiador inglês Theodore Zeldin (1996, p. D6), por exemplo, afirmou que o feminismo foi mais importante que a Revolução Russa de 1917.

De acordo com os princípios da "Nova História", o trabalho do historiador se alarga em direção a campos do conhecimento, sujeitos e objetos inexplorados. É o "outro" revelado pela antropologia e pela psicanálise que ecoa também na história. Para Saviani (1998, p. 9), tratase de "uma inflexão com a adoção de pressupostos estruturalistas oriundos da filosofia, da lingüística e da etnologia". Seguindo essa tendência, as fronteiras da história se estenderam de forma a permitir a incorporação da infância, do sonho, do corpo e mesmo do odor. É importante notar que, até a geração de Braudel, a história das mentalidades e outras formas de história cultural, embora não negligenciadas, situavamse marginalmente no projeto dos Annales. Entretanto, no transcurso dos anos de 1960 e 1970, conforme assinalou Burke (1991, p. 81), "o itinerário intelectual de alguns historiadores dos Annales transferiu-se da base econômica para a 'superestrutura' cultural, do 'porão ao sótão"'. Quanto ao perfil dessa terceira geração, ainda segundo o mesmo autor, é mais difícil traçá-lo; além do mais, ninguém neste período liderou o grupo como o fizeram Febvre e Braudel. Essa tendência atingiu enorme sucesso editorial, mas o risco da fragmentação conduziu a uma virada crítica no interior da escola, a partir de 1988, e foi então que se operou um retorno à história política e mesmo à dos eventos.

Contudo, por que considerar que a fragmentação da história é prejudicial se, ao mesmo tempo, revelou tantos horizontes e sujeitos 
antes desconhecidos ou ocultos? Para Dosse (1995, p. 12), cujo pensamento se identifica com as mudanças pragmáticas e hermenêuticas do movimento de recuperação da história política iniciado no final da década de 1980, há dois aspectos que merecem observação:

De um lado, a fecundidade dessa escola, mesmo do meu ponto de vista, que é ambivalente. É verdade que a fragmentação e a ampliação do campo do historiador permitiram o conhecimento de novos objetos, de novas problemáticas, uma interdisciplinaridade fecunda com as ciências sociais. Por outro lado, a expansão do território do historiador pode conduzir à compartimentação da disciplina histórica dentro dela mesma, pois cada especialista se preocupa com seu pequeno objeto e corre o risco de se confinar nele, perdendo a dimensão da globalidade, e a preocupação interpretativa, fazendo um trabalho estéril. Esse risco da fragmentação, aliás, foi percebido pelos historiadores dos "Annales" em 1988 e 1989.

Para Dosse, portanto, a "Nova História" reduziu a capacidade interpretativa da história a "um trabalho estéril", na medida em que, pela ausência da meta-história, que se fundamenta no princípio da "globalidade", ficou preocupada apenas com o "pequeno objeto" e acabou por ficar enredada "dentro dela mesma", ou seja, a expansão do "território do historiador", paradoxalmente, redundou numa posição epistemológica que, no passado, já fora criticada por Engels (1979, p. 21) quando observou que: "obcecado pelas árvores", o historiador "não consegue ver o bosque".

Por sua vez, Nosella e Buffa (2005, p. 354), analisando as tendências teórico-metodológicas que preponderaram no âmbito da pesquisa em história da educação brasileira, durante a última quadra do século XX, assinalaram que o interregno foi marcado:

(...) pela chamada crise dos paradigmas. Propõe-se, então, o pluralismo epistemológico e temático e privilegia-se o estudo de objetos singulares. $\mathrm{O}$ aspecto positivo dessa fase, que ainda hoje perdura, é representado pela ampliação das linhas de investigação, pela diversificação teóricometodológica e pela utilização das mais variadas fontes de pesquisa. Segundo alguns estudiosos, porém, o que está havendo é, na verdade, uma fragmentação epistemológica e temática que dificulta a compreensão da totalidade do fenômeno educacional. Muitos deles vêem, ainda nessa crise de paradigmas, um grande movimento antimarxista e o abandono da perspectiva histórica que privilegia temas como cultura 
escolar, formação de professores, livros didáticos, disciplinas escolares, currículo, práticas educativas, questōes de gênero, infância e, obviamente, as instituições escolares.

Contudo, no final da própria década de 1990 e no início do primeiro decênio do novo século, começaram a aparecer, de forma mais orgânica e unitária, as primeiras inflexões na hegemonia das tendências que protagonizaram a "fragmentação epistemológica e temática" no âmbito da pesquisa educacional. A contra-hegemonia empreendida pelos estudiosos que se colocavam em oposição ao "movimento antimarxista" e ao "abandono da perspectiva histórica" passou a atuar em uma nova conjuntura ideológica, marcada por dois acontecimentos interligados: de um lado, pelo fracasso da expectativa de que a "globalização" seria o remédio para todos os males produzidos pelo capitalismo da era neoliberal; de outro, porque os ditos novos paradigmas não conseguiram firmar um estatuto epistemológico orgânico e próprio. Em outras palavras: operou-se um deslocamento estrutural entre a lógica do desenvolvimento das forças produtivas (redução do trabalho vivo produtivo) e a pluralidade das tendências de pensamento (ideologias) que emergiram no contexto da chamada "revolução técnico-científica". Tal discrepância acabou por repercutir no âmbito das relaçôes que animavam ciência e filosofia, cuja consequência mais sentida foi o estabelecimento de uma separação artificial entre ambas, e que se acentuou, particularmente, nos últimos decênios do século XX. A fragmentação do conhecimento chegou a tal nível que cada ciência, de certo modo, acabou por produzir a sua própria "teoria do conhecimento", originando, assim, uma situação fecunda para o que se convencionou chamar de pós-modernidade. Ou seja: com o crepúsculo do século XX, foi se perdendo a importância das epistemologias que haviam sido engendradas pelos sistemas filosóficos que objetivavam a idéia de totalidade. ${ }^{4}$

Assim, entendendo que os ramos do saber sofrem um desenvolvimento cada vez mais rápido e desmesurado, os ideólogos pósmodernos alegam que um mesmo estudioso não pode mais estar a par de tudo e, muito menos, conhecer as "epistemologias" especializadas de cada área da produção científica. Esse foi, em síntese, o ambiente fecundo no qual se produziu a nova hegemonia no âmbito da pesquisa educacional, por meio dos "novos paradigmas emergentes". Contudo, a teoria do conhecimento que não se estrutura num valor geral (aquele fundado no conceito de totalidade) tende a se esfumar. É nesse 
sentido que os "novos paradigmas" se caracterizam por serem voláteis, pois não pertencem a nenhum sistema filosófico que se pauta pela metanarrativa e, por conseguinte, carecem de estatuto hermenêutico sistemático.

A concepção marxista da história e a pesquisa no campo da educação ${ }^{5}$

Para Marx, a história é um campo aberto de possibilidades. Um dos pressupostos de sua teoria da história é o de que os sujeitos atuam com determinadas intenções e finalidades, mas o processo histórico em si mesmo carece de intencionalidade, pois não existe nele um determinismo, uma finalidade imanente. Quanto à questão do método, ele aparece em Marx como a "ação reflexiva que permite ao sujeito apropriar-se da dinâmica do objeto" (Netto, 1998, p. 57). Nessa relação, o sujeito está autoimplicado no objeto, o que não significa identidade com ele, mas unidade, pois cabe ao sujeito reproduzir racionalmente o objeto, restituindo-lhe as suas múltiplas determinações.

Considerando o método criado por Marx, toda e qualquer formação social historicamente dada pode ser investigada com base em três categorias fundamentais: o singular, o particular e o universal. Se há em Marx o cuidado com a especificidade das distintas instâncias sociais, a categoria teórica da mediação passa a ter centralidade, pois, na verdade, a questão posta por ele é a "da análise da particularidade, que ele entende como um campo de mediações entre a universalidade e a singularidade" (idem, ibid., p. 60). Assim, o singular é a existência de objetos, fenômenos e instituições diversas, delimitados uns dos outros no espaço e no tempo e com uma determinação qualitativa e quantitativa individual (única). Vejamos como esse pressuposto pode ser aplicado ao estudo das instituiçóes escolares, por exemplo. A singularidade de uma determinada instituição societária exprime os seus elementos internos (constituição jurídica, objetivos sociais, representações políticas etc.) que a distinguem das outras instituições e são, por conseguinte, exclusivos dessa instituição e não de outra qualquer. Portanto, cada instituição não é mais que a parte do todo que forma um sistema societário integral e em constante transformação, produzida pelo movimento histórico gerado com base na luta entre elementos societários contraditórios.

Tomando como referência esse princípio, nenhuma instituição existe por si mesma. Ela não pode surgir, conservar-se ou mudar fora 
da conexão com uma quantidade de outras instituições e fenômenos sociais. Por outro lado, as características singulares e as relações que as instituições travam no âmbito de um determinado contexto histórico exprimem-se por meio da categoria do universal, que reflete a semelhança das características e aspectos que uma instituição guarda com outras instituiçôes, por meio das conexões entre elementos e partes de um sistema e também entre diferentes sistemas. Existe uma unidade e, ao mesmo tempo, uma luta dos contrários entre o universal e o singular: um não existe antes e fora do outro. Consequentemente, cada instituição historicamente construída se constitui numa unidade contraditória do universal e do singular, como, por exemplo, entre aquela que se manifesta no espaço delimitado pelo público e privado. Portanto, a categoria do particular desempenha o papel de um elo (mediação) entre o singular e o geral. Em relação ao singular (instituição), o particular pode ser um elemento do geral (uma determinada lei infraconstitucional), mas, em relação a uma generalidade ainda maior (Estado), o particular pode se transformar em uma categoria singular. Em síntese: o particular é uma formação relativamente isolada, uma instituição (um fenômeno educacional), um processo ou, até mesmo, um acontecimento. Já o singular constitui-se por traços e propriedades individuais e únicos inerentes ao particular, como, por exemplo, a instituição escolar no contexto de um sistema nacional de educação e os traços específicos que a diferenciam das outras instituições. ${ }^{6}$

As instituições, como fenômenos singulares, só existem historicamente no interior de uma determinada formação econômico-social. Por sua vez, a formação econômico-social não é um simples conglomerado de indivíduos ou agregado mecânico de fenômenos sociais independentes, mas é estruturada com base em um determinado sistema social que forma um todo, isto é, uma totalidade histórica. Neste sentido, cada um dos seus componentes societários não deve ser considerado em si mesmo isoladamente, mas unicamente em conexão com outros fenômenos sociais, pois cada um deles desempenha certo papel específico no funcionamento e desenvolvimento da sociedade; por conseguinte, estabelecem, por meio de mediações complexas e contraditórias entre eles, o sentido de realidade concreta que configura qualquer totalidade historicamente constituída. Assim, podemos afirmar que toda formação econômico-social é sempre um determinado tipo de sociedade historicamente constituída, ou seja, um sistema social integral 
que, portanto, funciona e se desenvolve segundo as suas leis específicas, na base do respectivo modo de produção que lhe garante, a um só tempo, tanto a existência material como a espiritual.

As instituições societárias como as escolares, por exemplo, estão historicamente vinculadas ao processo de desenvolvimento da vida material, política, social e cultural das formações econômico-sociais. $\mathrm{Na}$ perspectiva da vida material de existência da sociedade, a instituição escolar estabelece uma complexa e contraditória relação com o mundo do trabalho. Assim, a relação entre educação e trabalho é, em última instância, uma contingência histórica determinada pelo reino das necessidades elementares que mantêm os homens desenvolvendo plenamente as suas atividades societárias. Portanto, a relação entre instituição escolar e mundo do trabalho (fábricas, serviços, fazendas etc.) se insere no âmbito mais geral das relações econômicas que se desenvolvem no processo de produção dos bens materiais, ou seja, uma das formas fundamentais da atividade humana. Esse tipo específico de relação exprime também a capacidade científica e tecnológica de transformação da natureza pela ação dos homens. Neste sentido, a instituição escolar está diretamente vinculada às relações entre produção e consumo dos bens materiais necessários (e desnecessários também) à vida das sociedades, ou seja, são relaçôes primárias e elementares na esfera da vida cotidiana e familiar.

Quanto ao desenvolvimento político-social, a instituição escolar, via de regra, funciona como um aparelho de reprodução das relaçôes ideológicas. As expressões ideológicas se desenvolvem no âmbito da consciência social e incluem as idéias jurídicas, políticas, morais, religiosas, pedagógicas etc. Neste caso, a instituição escolar reproduz um conjunto de idéias e relações sociais que surgem sobre o fundamento de uma determinada base econômica, mas que guardam independência criativa com as próprias relações sociais de produção que as engendraram. Tanto é assim que as idéias, notadamente as filosóficas, continuam existindo e influenciando épocas muito distintas daquelas em que foram geradas. No mundo contemporâneo, dadas as consequências da revolução técnico-científica, as ideologias desempenham um papel extremamente ativo no processo histórico. Já no processo de desenvolvimento espiritual da sociedade, a instituição escolar se vincula de forma orgânica com a cultura desinteressada, denominada também de artes liberais. As chamadas disciplinas de humanidades têm desempenhado, 
historicamente, uma função preponderante no desenvolvimento do espírito humano, desde que os gregos inventaram a instituição escolar na Antiguidade clássica.

A concepção marxista da história parte do pressuposto de que a dependência das instituiçôes superestruturais, em relação à base econômica que garante a existência material da sociedade, não deve ser compreendida de forma simplista, como um mecanismo que atua automaticamente. Quaisquer transformações no interior de uma instituição escolar, por exemplo, não podem ser tomadas exclusivamente por causas geradas no âmbito das relaçôes sociais de produção, pois as próprias instituiçôes superestruturais, movidas por um conjunto complexo e contraditório de causas (políticas, ideológicas, religiosas, culturais, pedagógicas etc.), acabam por estabelecer entre si múltiplas interaçōes que têm consequências nem sempre condicionadas economicamente. Dito de outra forma: a economia determina a natureza própria da instituição escolar somente em última instância, pois, no fundamental, é sempre necessário que se investigue o desenvolvimento da lógica interna da instituição escolar, buscando perceber o paradigma educacional por meio do qual a sua história foi se constituindo, isto é, procurando estabelecer os nexos por meio dos quais se viabilizaram as concretas relaçôes entre a própria instituição e a sociedade que lhe conferia sustentação.

A escola atua e se justifica socialmente como uma instituição que miniaturiza, no seu interior, uma relação complexa entre esses quatro tipos de desenvolvimentos societários: material, social, político e espiritual. A preponderância de um sobre os outros, ou de três sobre um, ou, ainda, o justo equilíbrio entres eles guarda, no âmbito pedagógico de uma instituição escolar, relação direta com as necessidades impostas por cada época historicamente determinada. Em síntese: a mediação que a instituição escolar desempenha entre relações materiais e ideológicas permite evidenciar os conceitos históricos, sociológicos, filosóficos e pedagógicos que caracterizam a estrutura e a especificidade qualitativa de uma dada formação societária.

\section{Conclusão}

A partir da última década do século $\mathrm{xx}$, com a crise do marxismo, ${ }^{7}$ o campo da história da educação passou a ser hegemonizado pelas concepções pós-modernas presentes no âmbito da historiografia. 
Desde então, a história da educação incorporou os objetos de estudo da história das mentalidades, da vida cotidiana, da micro-história, da história das mulheres, da cultura etc. Essa fragmentação dos fenômenos investigados pela história da educação coloca-se em oposição às concepções estruturais que, até então, haviam influenciado os estudos históricos no Brasil: o positivismo, o marxismo, e a própria Escola dos Annales, nas suas primeiras gerações. Na perspectiva hegemônica, o deslocamento do foco da pesquisa para os estudos microscópicos desobriga o historiador de estudar o significado que o movimento mais geral e estrutural dos acontecimentos econômicos, sociais e políticos imprime nas totalidades societárias, particularmente do ponto de vista das rupturas históricas.

Já as últimas tendências historiográficas concebem micro-objetos desvinculados de um todo orgânico e, ao mesmo tempo em que elas se tornaram hegemônicas, ocorreu também aquilo que Cardoso (1997, p. 19) denominou de "desleixo metodológico", aspecto que, no campo da pesquisa em educação, tem gerado estudos frágeis e de "trajetos curtos", conforme analisou Gatti (2003, p. 5):

Historicamente observa-se que estudos para serem tomados como conhecimento relevante e ter penetração social, mais amplamente, ou regional ou localmente, precisam carregar em si um certo tipo de possibilidade de abrangência, com aderência ao real, tocando de forma inequívoca, não ambígua, vaga ou arbitrária, em pontos críticos do concreto educacional vivido.

As tendências hegemônicas, quando tratam das mudanças, não as consideram como fruto das contradiçóes geradas no âmbito das relaçôes protagonizadas pelas classes sociais antagônicas inerentes ao capitalismo, mas, sim, por decorrência de atitudes produzidas, por exemplo, no seio das "elites culturais". A "história em migalhas" em que se transformou grande parte da história da educação está diretamente relacionada com a concepção historiográfica que abandonou a preocupação com os movimentos explicativos da totalidade societária e imprimiu apenas significados singulares para cada um dos objetos estudados.

Quanto ao marxismo, conforme referido anteriormente por Cardoso (1997), existe uma proximidade de interpretação entre ele e as primeiras geraçóes da Escola dos Annales. Concluiremos este artigo com referências mais explícitas sobre essa relação. Assim, se considerarmos 
que a grande mudança epistemológica produzida pelos Annales não se constituiu propriamente na interdisciplinaridade, mas, sim, naquilo que a tornou possível, ou seja, a nova representação do tempo (Reis, 1998) - ou longa duração - e que essa representação do tempo histórico, segundo Braudel, consiste na ênfase aos condicionamentos econômico-sociais, isto é, nas "condições materiais e não nos projetos individuais, subjetivos e ideológicos" (idem, ibid., p. 31), constataremos que essa mesma abordagem crítica à história tradicional já estava consignada na obra. $A$ ideologia ale$m \tilde{a}$. Seus autores, ao considerarem os homens não isolados ou fixos, mas apreendidos no seu processo de desenvolvimento real, assim escreveram: "desde que se represente este processo de atividade vital, a história deixa de ser uma coleção de fatos sem vida, como a apresentam os empiristas, e que são ainda abstratos, ou a ação imaginária de sujeitos imaginários, como a apresentam os idealistas" (Marx \& Engels, 1980, v. I, p. 26-27). Marx busca encontrar, no processo histórico, regularidades que, no vocabulário da sua época, recebiam o nome de leis; já os fundadores dos Annales querem buscar as permanências, aquilo que resiste e não o que é passageiro na história, por isso, o conceito de longa duração e, em ambas as concepções - a marxista e a dos Annales -, a importância das condições materiais. Da mesma forma, a renovação dos estudos históricos pelo alargamento do conceito de fonte já estava presente nos procedimentos de Marx, que, além do documento oficial, recorreu a todo um recurso heurístico, abrangendo a biografia e o memorialismo da época, uma vez que seu método de análise para distinguir aparência de essência consistia em considerar sempre a observação direta e a observação indireta (Netto, 1998).

Finalmente, no tocante à idéia expressa na introdução deste artigo sobre a contribuição que o marxismo pode prestar à pesquisa educacional, enfatizamos a sua importância como método de análise, embora seja preciso considerar também que nenhum postulado teórico-metodológico é garantia de êxito de qualquer pesquisa. No caso da epistemologia marxista, se tivermos em conta a forma de trabalho adotada por Marx, essa assertiva ganha ainda maior sentido, uma vez que foram pouquíssimas as vezes em que ele dedicou atenção autônoma ao tratamento de problemas metodológicos, o que, segundo Netto (1998, p. 56), não foi algo espontâneo, mas "se explica pelo fato de que nele o interesse epistemológico está sempre subordinado à direção ontológica da sua reflexão". Nesta perspectiva, nada mais estranho à epistemologia fundada por Marx do que aquele típico capítulo teórico-metodológico das dissertações e 
teses acadêmicas das décadas de 1970 e 1980, anunciando os supostos teóricos que, raramente, mantinham vinculação orgânica com o objeto. Essa tendência, conquanto muito presente na produção que apontava o marxismo como referencial teórico, não foi exclusiva dela, predominando também em outras correntes epistemológicas que marcaram e continuam marcando o campo da produção acadêmica educacional. Se no padrão acadêmico atual o "capítulo teórico" inicial caiu em desuso, continuamos a padecer de males semelhantes, pois, conforme escreveu Gatti (2003, p. 1), observa-se ausência de mediaçôes interpretativas na forma pela qual os autores de trabalhos acadêmicos tratam as informações bibliográficas disponíveis, tanto na construção de referentes teóricos, como nas análises e interpretações:

Quantas e quantas vezes não vemos as mesmas citações de Saviani, Freire, Libâneo, Bourdieu, Marx, Piaget, Schon, Zeichner, Perrenoud, Nóvoa, Enguita, etc., repetidas, pois, não se processa uma revisão bibliográfica como uma "reconstrução" ativa, com uma perspectiva pessoal interpretativo-crítica sobre o tema.

Em outras palavras, reproduzir citações não é garantia de que uma dissertação ou tese acadêmica tenha, de fato, feito jus ao pensamento daquele que é citado, porque a incorporação do método deve estar subjacente à análise do objeto. Desse modo, se considerarmos o método de trabalho de Marx, todo o cuidado deve ser tomado para não fazer de uma referência teórico-metodológica uma maneira de estreitar e empobrecer o objeto. A formação teórico-metodológica é um dos componentes da investigação e deve ser um componente fundamental. Contudo, ela não pode substituir o profundo conhecimento que se deve ter sobre o objeto da investigação. Além disso, para o pleno êxito da pesquisa, isto é, para a obtenção de um resultado rico e relevante, esses dois aspectos postulado teórico-metodológico e profundo conhecimento do objeto devem ser adicionados à cultura ampla que se requer de todo pesquisador em ciências humanas.

Recebido em novembro de 2007 e aprovado em abril de 2008.

\section{Notas}

1. Para um entendimento mais sistemático da categoria filosófica de totalidade, digno de nota é Lukács (1979, p. 238 ss.). 
História, epistemologia marxista e pesquisa educacional brasileira

2. A respeito do predomínio do positivismo no campo da História da Educação, ver Buffa (2001, p. 80-81).

3. Já sobre a influência do marxismo não-dialético no âmbito das pesquisas em educação, consultar Ferreira Jr. \& Bittar (2005, p. 68-69).

4. Sobre a aplicação do referencial teórico-metodológico do marxismo na área das pesquisas que têm como objeto de investigação as instituiçôes escolares, conferir Nosella \& Buffa (2005, p. 358 ss.).

5. Todas as referências aos princípios, leis e categorias concernentes à concepção marxista da história utilizadas neste item do texto encontram-se em: Engels (1979, p. 81 ss.), Marx (1971a, p. 27; 1971b, p. 228 ss.; 2004, p. 115 ss.); Marx \& Engels (1980, p. 29 ss.; 1982, p. 106 ss.).

6. Sobre a importância de se aplicar o procedimento metodológico que estabelece a relação entre o singular e o geral no processo de investigação das instituições escolares, os seguintes artigos de Sanfelice são merecedores de exame: "História de instituições escolares: apontamentos preliminares" (2002) e "História, instituições escolares e gestores educacionais" (2006).

7. No contexto da década de 1990 , Frigotto $(1998$, p. 26) afirmou o seguinte sobre a crise vivida pelo marxismo: "Ao anunciar esta opção, é importante sublinhar dois aspectos relevantes para evitar, in limine, a interpretação que estejamos nos alinhando a uma perspectiva dogmática ou doutrinária. O primeiro aspecto é o reconhecimento de que o marxismo, enquanto concepção epistemológica e, também, como orientação ético-política, está efetivamente em crise e que, portanto, há necessidade de não apenas reconhecer a superação de algumas análises datadas de Marx e Engels, mas de historicizar o núcleo fundamental de sua teoria (Hobsbawm, 1997; Konder, 1992, 1996)".

\section{Referências}

ALENCASTRO, L.F. Consenso de bacharéis. Folha de S. Paulo, São Paulo, 4 dez. 1994. Caderno 6, p. 7-8.

BOURDIEU, P. Método científico e hierarquia social dos objetos. In: Nogueira, M.A.; Catani, A. (Org.). Escritos de educação. 3. ed. Petrópolis: Vozes, 2001. p. 31-38.

BUFFA, E. A questão das fontes de investigação em história da educação. Série Estudos, Campo Grande, n. 12, p. 79-86, jul./dez. 2001. BURKE, P. A Revolução Francesa da historiografia: a Escola dos Annales (1929-1989). Trad. Nilo Odália. São Paulo: UNESP, 1991.

CARDOSO, C.F. Paradigmas rivais na historiografia atual. Educação \& Sociedade, Campinas, v. 15, n. 47, p. 61-72, abr. 1994.

CARDOSO, C.F. Para Ciro Flamarion época de transição explica impasse teórico. Registro: Informativo do Centro Nacional de Referência 
Historiográfica, Mariana, n. 3, p. 4-6, mar./ago. 1995. Entrevistadores: Carla Maria Carvalho de Almeida e Ronaldo Pereira de Jesus.

CARDOSO, C.F. História e paradigmas rivais. In: CARdoso, C.F.; VAINFAs, R. (Org.). Domínios da história: ensaios de teoria e metodologia. Rio de Janeiro: Campus, 1997.

DOSSE, F. A história em migalhas: dos “Annales" à "Nova História”. Trad. Dulce da Silva Ramos. São Paulo: Ensaio; Campinas: Editora da UNICAMP, 1992.

DOSSE, F. A mania da fragmentação. Folha de S. Paulo, São Paulo, 6 ago. 1995. Caderno 5, p. 12. (Entrevista realizada por Sheila Schvarzman).

ENGELS, F. Anti-Dühring: filosofia, economia política, socialismo. 2. ed. Rio de Janeiro: Paz \& Terra, 1979.

FERREIRA Jr., A.; BITTAR, M. O marxismo como referencial teórico nas dissertações de mestrado em educação da UFSCAR (1976-1993). Cadernos CEMARX, Campinas, v. 1, n. 2, p. 65-71, 2005.

FRIGOTTO, G. Educação, crise do trabalho assalariado e do desenvolvimento: teorias em conflitos. In: FrigotTo, G. (Org.). Educação e crise do trabalho: perspectivas de final de século. Petrópolis: Vozes, 1998. p. 25-54.

GATTI, B. A pesquisa em educação: pontuando algumas questões metodológicas. Campinas, out. 2003. Disponível em: <http:// www.lite.fae.unicamp.br/revista/gatti.html>. Acesso em: 18 nov. 2007.

LUKÁCS, G. Existencialismo ou marxismo. Trad. José Carlos Bruni. São Paulo: Ciências Humanas, 1979.

MARX, K. Prefácio. In: MARX, K Contribuição para a crítica da economia politica. Trad. Maria Helena Barreiro Alves. Lisboa: Estampa, 1971a. p. 27- 31.

MARX, K. Método da economia política. In: MARX, K. Contribuição para a critica da economia politica. Trad. Maria Helena Barreiro Alves. Lisboa: Estampa, 1971b. p. 228-237.

MARX, K. Manuscritos econômico-filosóficos. Trad. Jesus Ranieri. São Paulo: Boitempo, 2004. 
MARX, K.; ENGELS, F. Feuerbach. In: MarX, K.; Engels, F. A ideologia alemã. Trad. Conceição Jardim et al. 4. ed. Portugal: Presença; São Paulo: Martins Fontes, 1980. v. 1, p. 11-102.

MARX, K.; ENGELS, F. Manifesto do Partido Comunista. In: MarX, K.; Engels, F. Obras escolhidas em três tomos. Trad. Álvaro Pina. Lisboa: Avante!; Moscovo: Progresso, 1982. p. 93-136.

NETTO, J.P. Relendo a teoria marxista da história. In: SAVIANI, D.; Lombardi, J.C.; Sanfelice. J.L. (Org.). História e história da educação: o debate teórico-metodológico atual. Campinas: Autores Associados; HISTEDBR, 1998. p. 50-64.

NOSELLA, P.; BUFFA, E. As pesquisas sobre instituições escolares: o método dialético marxista de investigação. EccoS, São Paulo, v. 7, n. 2, p. 351-368, jul./dez. 2005.

REIS, J.C. Os Annales: a renovação teórico-metodológica e "utópica" da história pela reconstrução do tempo histórico. In: SAVIAni, D.; Lombardi, J.C.; Sanfelice. J.L. (Org.). História e história da educação: o debate teórico-metodológico atual. Campinas: Autores Associados; HISTEDBR, 1998. p. 25-49.

SANFELICE, J.L. História de instituições escolares: apontamentos preliminares. Revista HISTEDBR On-line, Campinas, n. 8, out. 2002. Disponível em: <http://www.histedbr.fae.unicamp.br/rev8.html>. Acesso em: 8 set. 2007.

SANFELICE, J.L. História, instituições escolares e gestores educacionais. Revista HISTEDBR On-line, Campinas, n. 22 (especial), p. 20-27, ago. 2006. Disponível em: <http://www.histedbr.fae.unicamp.br/ art4_22e.pdf>. Acesso em: 8 set. 2007.

SAVIANI, D. Entrevista. Campinas, 19 de julho de 1995. Entrevistadores: Amarilio Ferreira Jr. e Marisa Bittar.

SAVIANI, D. O debate teórico e metodológico no campo da História e sua importância para a pesquisa educacional. In: SAVIANI, D.; Lombardi, J.C.; Sanfelice. J.L. (Org.) História e história da educação: o debate teórico-metodológico atual. Campinas: Autores Associados; HISTEDBR, 1998. 
SCHILLING, P.R. O fim da história ou o colapso da modernidade?: (o fracasso do neoliberalismo na América Latina). São Paulo: CEDI; Koinonia, 1994.

ZAIDAN FILHO, M. A crise da razão histórica. Campinas: Papirus, 1989.

ZELDIN, T. Theodore Zeldin quer ser um incômodo. O Estado de $S$. Paulo, São Paulo, 21 set. 1996. p. D6. Entrevista realizada por Carlos Graieb. 